\title{
ДОСЛІДЖЕННЯ СИСТЕМИ "ОРИГІНАЛ-ВІДБИТОК" ІЗ ВИЗНАЧЕННЯМ ВПЛИВУ ÏI ПАРАМЕТРІВ НА СТАБІЛЬНІСТЬ ПРОЦЕСУ РЕПРОДУКУВАННЯ ПЛОСКИМ ОФСЕТНИМ ДРУКОМ
}

( Я. В. Зоренко, аспірант, НТУУ «КПІ», Київ, Україна

\begin{abstract}
Определены существенные факторы процесса репродуцирования плоской офсетной печатью и взаимосвязь градационных, оптических и цветностных свойств системы «оригинал-оттиск». С помощью регрессионного анализа определено влияние режимов цветоделения оригиналмакета в офсетной плоской печати на оптические свойства репродукции.
\end{abstract}

The main parameters in offset printing reproductions processes and interaction between optical, halftone and color properties in the system «original-print» were considered. The influencing of color separation modes at tone image processing to optical properties of offset printing was defined by using the method of regressive analysis.

\section{Постановка проблеми}

Сучасний плоский офсетний друк характеризується постійною потребою у забезпеченні стабільного тоно- та кольоровідтворення тиражного відбитку, що можливе за допомогою засобів контролю і управління властивостями процесу репродукування на всіх етапах відтворення графічної інформації. Найбільш поширеними засобами управління та контролю за процесом репродукування плоским офсетним друком $€$ шкали контролю і методи їх оцінки. Зокрема розробки таких компаній як FOGRA, UGRA, Brunner, Heidelberg, Gretag та X-Rite [1-4].

Параметри контролю для плоского офсетного друку у більшості випадках залишаються не змінними, тобто дозволяють визначати та аналізувати стандартні показники якості, а саме оптичну густину, ступінь розтискування, колірні відмінності. Більшість існуючих алгоритмів контролю та управління параметрами репродукції зводяться до процесу вимірювання та порівняння показників контрольної шкали (спеціально розробленої тестформи) із еталонними значеннями, причому сам процес контролю застосовуються при записі графічної інформації на формному матеріалі і в процесі друку [5-6].

Тоновий оригінал у процесі репродукування плоским офсетним друком проходить низку перетворень у системі «оригінал-відбиток». Причому система «оригінал-відбиток» $є$ дуже складною за своєю структурою, оскільки складається із підсистем, які характеризуються взає- 
модією великої кількості параметрів та факторів етапів підготовки оригінал-макету, формного та друкарського процесів. Також, потрібно враховувати невеликий досвід практичного застосування новітніх технологій, наприклад, гібридних алгоритмів растрування. Тому дослідження процесу репродукування із застосуванням новітніх технологій плоского офсетного друку та моделювання системи «оригіналвідбиток» для визначення впливу її параметрів на стабільність відтворення тиражного відбитку $€$ актуальним напрямком досліджень.

\section{Аналіз попередніх досліджень}

Аналіз сучасних досліджень присвячених проблематиці процесу репродукування плоским офсетного друком виявив суттєвий інтерес науковців до методів контролю за процесами поліграфічного відтворення графічного оригіналу [7-11]. Так, зокрема у роботі [8] запропонована методика визначення та контролю якості відтворення інформації на відбитку в офсетному друці в системі «фотоформадрукарська форма-відбиток» та «друкарська форма-відбиток» для технологій CtF та CtP відповідно. Дана методика дозволяє комплексно контролювати такі показники як: площу растрової крапки, вертикальні та горизонтальні штрихові елементи, ширину 3'єднувального та проміжного штриху літери «Н» та ін.

Існуючі дослідження стосуються переважно розробок методів ідентифікації та контролю якості відбитка, так вченими розроблена методика для порівняння показника ахроматичності і яскравості для цифрових моделей досліджуваного і еталонного зображення [9].

Також досліджувалася якість цифрових технологій відтворення оригіналу на основі розробленого інтегрального показника оцінки колірного охоплення колірних систем, а також методів ïx практичного визначення [10]. Вказаний показник враховує особливості колірного сприйняття людини за допомогою уточненої функції колірних відмінностей $\Delta \mathrm{E}_{\infty}$ і дозволяє об'єктивно оцінити колірне охоплення репрографічних систем відтворення графічної інформації.

У інших дослідженнях [11-13] більше уваги сконцентровано на управління параметрами формного обладнання. Зокрема розроблена просторова модель [10] процесу запису графічної інформації (електронного оригіналу) на формний матеріал у системах оптичного поелементного запису растрових зображень дозволила визначити ступінь впливу факторів процесу запису на параметри якості растрової структури, зокрема оптичну густину в центрі растрових крапок і на плашці, ореол розмиття, точність відтворення растрових крапок тощо.

\section{Мета дослідження}

Встановлення характеру взаємодії параметрів системи «оригінал-відбиток» плоского офсетного друку та моделювання етапів репродукування для стабілізації технологічного процесу відтворення тонового оригіналмакету. 


\section{Результати проведених досліджень}

На підставі аналітико-математичного обґрунтування параметрів контролю процесу репродукування та теорії множин і комбінаторики [14] було проаналізовано систему «оригіналвідбиток». Для подальшого розвитку технологічних основ управління процесом репродукування шляхом увиразнення аналітико-математичного виразу параметрів репродукції, згідно теорії множин і комбінаторики систему «оригінал-відбиток» було представлено як стохастичну та ієрархічну систему із низкою параметрів досліджуваного процесу репродукування, аналогу системи «оригінал-відбиTOK»:

$$
R=\left\{A \cup B \cup C \cup\left[\frac{B \cup C}{N}\right]\right\}
$$

де множина елементів: $\mathrm{R}-$ процес репродукування; A процес підготовки оригінал-макету (підсистема «оригінал-фотоформа»; В - формний процес (підсистема «фотоформа-друкарська форма»); C - процес друкування (підсистема «друкарська форма-відбиток»); $\mathrm{N}$ стохастичність (зниження якості) процесу репродукування.

Згідно правил комбінаторики [14] при додаванні та відніманні підмножин процес підготовки оригінал-макету (множина A), формний процес (множина В) та процес друкування (множина С) можна записати наступним чиHOM:

$$
\mathrm{A}=\left\{\mathrm{O}_{1} \cap \mathrm{O}_{2} \cap \mathrm{O}_{3} \cap \mathrm{O}_{4}\right\},
$$

$$
\begin{aligned}
& \mathrm{B}=\left\{\mathrm{O}_{4} \cap \mathrm{O}_{5}\right\}, \\
& \mathrm{C}=\left\{\mathrm{O}_{5} \cap \mathrm{O}_{6}\right\},
\end{aligned}
$$

де множина елементів A, B та С включає наступні підмножини 1-го порядку: $\mathrm{O}_{1}-$ тоновий оригінал; $\mathrm{O}_{2}$ - цифровий оригінал; $\mathrm{O}_{3}$ - растровий кольороподілений оригінал (цифрова кольоропроба); $\mathrm{O}_{4}-$ фотоформа; $\mathrm{O}_{5}$ - друкарська форма; $\mathrm{O}_{6}-$ відбиток (репродукція).

Згідно ієрархічної побудови процесу репродукування було виділено наступні підмножини 2-го рангу:

$$
\begin{gathered}
\mathrm{O}_{1}=\left\{\mathrm{D}_{1}^{\mathrm{op}} \cup \mathrm{K}_{1}^{\mathrm{op}} \cup \mathrm{Z}_{1}^{\mathrm{op}}\right\} \\
\mathrm{O}_{2}=\left\{\mathrm{D}_{2}^{\mathrm{op}} \cup \mathrm{K}_{2}^{\mathrm{op}} \cup Z_{2}^{\mathrm{op}} \cup \mathrm{X}_{2}^{\mathrm{op}}\right\} \\
\mathrm{O}_{3}=\left\{\mathrm{D}_{3}^{\mathrm{op}} \cup \mathrm{K}_{3}^{\mathrm{op}} \cup Z_{3}^{\mathrm{op}} \cup \mathrm{X}_{3}^{\mathrm{op}}\right\} \\
\mathrm{O}_{4}=\left\{\mathrm{D}_{4}^{\mathrm{op}} \cup \mathrm{E}_{4}^{\mathrm{op}} \cup Z_{4}^{\mathrm{op}} \cup \mathrm{X}_{4}^{\mathrm{op}}\right\} \\
\mathrm{O}_{5}=\left\{\mathrm{D}_{5}^{\mathrm{op}} \cup \mathrm{E}_{5}^{\mathrm{op}} \cup Z_{5}^{\mathrm{op}} \cup \mathrm{X}_{5}^{\mathrm{op}}\right\}, \\
\mathrm{O}_{6}=\left\{\mathrm{D}_{6}^{\mathrm{op}} \cup \mathrm{E}_{6}^{\mathrm{op}} \cup Z_{6}^{\mathrm{op}} \cup \mathrm{X}_{6}^{\mathrm{op}}\right\},
\end{gathered}
$$

де Dop - градаційні характеристики; Кор - колірні характеристики; Еор - спектральні характеристики; Zop - структурні та геометричні характеристики; Хор - технологічні параметри (режими).

Застосовуючи вирази (5-10) елементів множини процесу репродукування $\mathrm{R}$ та враховуючи взаємодію різних параметрів (2-4) процес репродукування (1) можна записати у вигляді, 


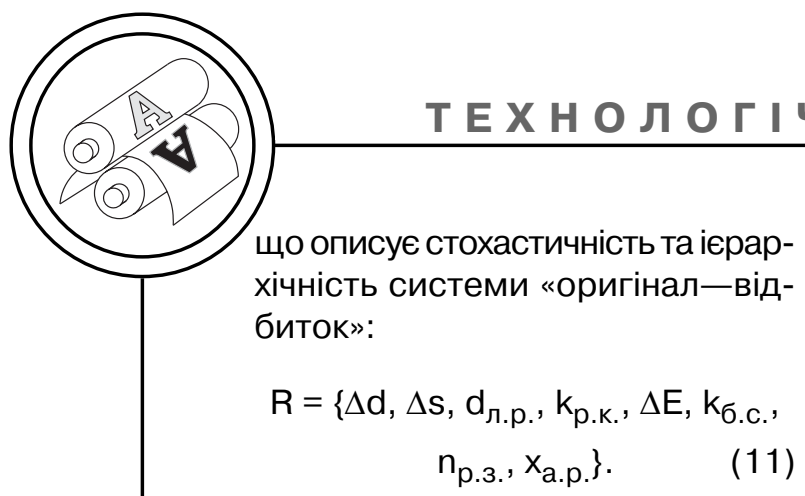

Аналітичний вираз (11) описує взаємозв'язок параметрів управління і впливу репродукції як технологічного об'єкта: інтервал оптичної густини $(\Delta d)$, або різниця між максимальною $\left(d_{\max }\right)$ та мінімальною оптичною густиною $\left(d_{\min }\right)$; величина спотворень відносної площі растрових елементів ( $\Delta \mathrm{s})$; лініатура растру $\left(\mathrm{d}_{\text {л.р. }}\right)$; режим кольороподілу $\left(\mathrm{k}_{\text {р.к. }}\right)$; колірні відмінності $(\Delta \mathrm{E})$; баланс «по-сірому» $\left(\mathrm{k}_{\text {б.с. }}\right)$; роздільна здатність вивідного пристрою $\left(\mathrm{n}_{\mathrm{p.z.}}\right)$; алгоритм растрування ( $\left.\mathrm{x}_{\text {a.p. }}\right)$.

Вираз (11) увиразнює поліграфічну репродукцію як технологічний об'єкт - продукт технологічного процесу, що описується взаємодією зазначених параметрів, які піддаються контролю, i, в той же час, є факторами впливу - як технологічні параметри, які можна регулювати.

Для об'єктивної оцінки якості відтворення репродукції на різних етапах відтворення оригіналу запропоновано застосування методики визначення функції передачі модуляції (ФПМ) зображення [15]:

$$
M_{i}^{j}=\frac{D_{i \max }^{j}-D_{i \min }^{j}}{D_{i \max }^{j}+D_{i \min }^{j}},
$$

$$
\text { де } \mathrm{M}_{\mathrm{i}}^{\mathrm{j}} \text { - модуляція сигналу }
$$

зображення на і-му носії інформації (оригінал, фотоформа, друкарська форма чи відбиток) та ј-го кольору (чорно-біле чи повноколірне зображення); $D_{i}^{j}-$ оптична густина (інтенсивність тону) і-го носія інформації та ј-го кольору.

На основі виразів $(2-4,11)$ можна записати спрощену математичну модель процесу репродукування (див. рис. 1) для прогнозування впливу відхилень показників системи «оригіналвідбиток» на величину ФПМ оригіналу (12) у процесі відтворення репродукції плоским офсетним друком [8]:

$$
\begin{aligned}
& M_{0} \geq \frac{1}{G_{1}} M_{1} \leq \\
& \leq \frac{1}{G_{2}} M_{2} \leq \frac{1}{G_{3}} M_{3},
\end{aligned}
$$

де $M_{0}, M_{1}, M_{2}, M_{3}-Ф П M$ відповідно для оригіналу, фотоформи, друкарської форми та відбитку. $\mathrm{G}_{1}, \mathrm{G}_{2}, \mathrm{G}_{3}$ - сукупність чинників, що впливають на коливання величини ФПМ відповідно у підсистемі «оригінал-фотоформа», «фотоформа-друкарська форма» та «друкарська форма-відбиток».

Застосовуючи нормовані значення оптичної густини для виразу (13) було розраховано межі варіювання коефіцієнту ФПМ, для підсистеми «оригінал-фотоформа» значення коефіцієнту ФПМ складає $\mathrm{M}_{0}=\mathrm{M}_{1}=84 . . .97$; для підсистеми «фотоформадрукарська форма» - ФПМ складає $\mathrm{M}_{2}=0,90 \ldots 0,95$.

Найсуттєвішими чинниками (G) впливу на коефіцієнт ФПМ у підсистемах «оригінал-фотоформа» та «фотоформа-дру- 
карська форма» згідно виразу (11) є застосований режим кольороподілу (виражений за градаційним діапазоном чорного кольору $\mathrm{S}_{г р . к}$ при відтворенні нейтрально-сірих тонів) та формні технології (технології растрування і виготовлення друкарських форм). Тому, встановлення закономірностей зміни коефіцієнту ФПМ в межах процесу репродукування може бути виражено кореляційним зв'язком між параметрами регресійного рівняння підсистеми «друкарська форма-відбиток» [16]:

$$
\begin{gathered}
\mathrm{M}_{3}=\mathrm{b}_{0}+\mathrm{b}_{1} \Delta \mathrm{d}+\mathrm{b}_{2} \Delta \mathrm{s}+\mathrm{b}_{3} \Delta \mathrm{E}+ \\
+\mathrm{b}_{4} \mathrm{k}_{\text {б.c. }}+\mathrm{b}_{12} \Delta \mathrm{d} \cdot \Delta \mathrm{s}+\mathrm{b}_{13} \Delta \mathrm{d} \cdot \\
\cdot \Delta \mathrm{E}+\mathrm{b}_{14} \Delta \mathrm{d} \cdot \mathrm{k}_{\text {б.c. }}+\mathrm{b}_{23} \Delta \mathrm{s} \cdot \\
\cdot \Delta \mathrm{E}+\mathrm{b}_{24} \Delta \mathrm{s} \cdot \mathrm{k}_{\text {б.c. }}+\mathrm{b}_{34} \Delta \mathrm{E} \cdot \\
\cdot \mathrm{k}_{\text {б.c. }}+\mathrm{b}_{123} \Delta \mathrm{d} \cdot \Delta \mathrm{s} \cdot \Delta \mathrm{E}+ \\
+\mathrm{b}_{124} \Delta \mathrm{d} \cdot \Delta \mathrm{s} \cdot \mathrm{k}_{\text {б.c. }}+\mathrm{b}_{134} \Delta \mathrm{d} \cdot \\
\cdot \Delta \mathrm{E} \cdot \mathrm{k}_{\text {б.с. }}+\mathrm{b}_{234} \Delta \mathrm{s} \cdot \Delta \mathrm{E} \cdot \\
\cdot \mathrm{k}_{\text {б.с. }}
\end{gathered}
$$

Підсистема «друкарська форма-відбиток» $€$ найбільш нестабільною тому визначення меж варіювання коефіцієнту ФПМ для друкарського процесу $\left(\mathrm{M}_{3}\right) \in$ доволі важливим.

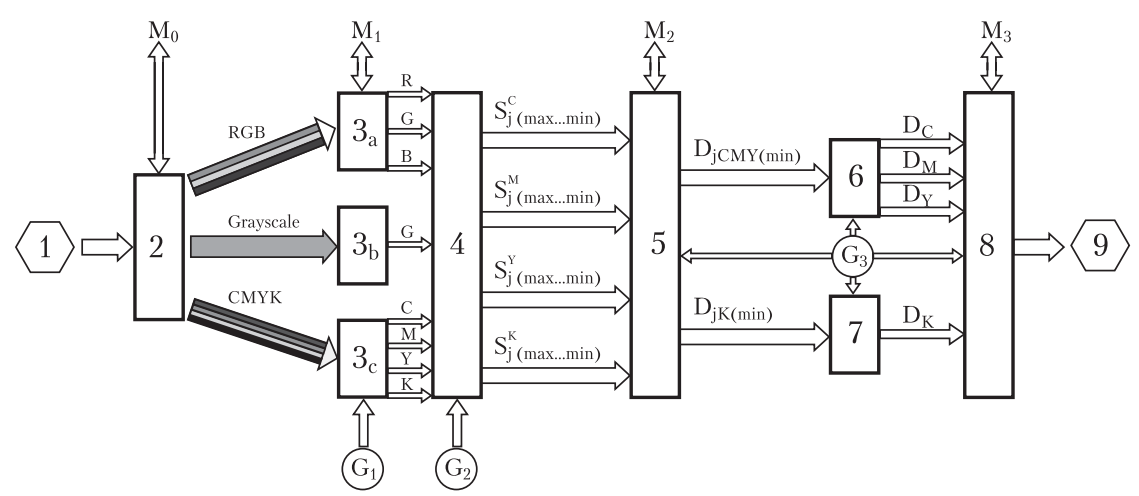

Рис. 1. Модель технологічного процесу репродукування: 1 - оригінал; 2 - система (канали) зчитування інформації (RGB, CMYK, Grayscale); За, 3b, 3c - невідкоректовані сигнали діапазону оптичних густин оригіналу $\left(D_{i(\max . . . m i n)}\right)$ за різними колірними системами відповідно, де i - канал зчитування інформації (червоний, зелений, блакитний, відтінки сірого, блакитний, пурпурний, жовтий, чорний); 4 - перетворення сигналів $\left(D_{i(\max . . . m i n)}\right)$ для формування відносної площі растрових елементів при синтезі кольору $\left(\mathrm{S}_{\mathrm{j}(\max . . . \mathrm{min})}\right)$, де $\mathrm{j}$ - фарба (блакитна, пурпурова, жовта, чорна); 5 - розрахунок мінімальної оптичної густини фарби $\left(\mathrm{S}_{\mathrm{CMYK}(\mathrm{min})}\right) ; 6$ - перетворення сигналів для кольороподілу зображення і виділення блакитної, пурпурової та жовтої фарб $\left(\mathrm{D}_{\mathrm{CMY}(\min )}\right) ; 7$ - перетворення сигналів для кольороподілу зображення і виділення чорної фарби $\left(\mathrm{D}_{\mathrm{K}(\mathrm{min})}\right) ; 8$ - формування (синтез) колірного відтінку зображення на папері; 9 - відбиток плоского офсетного друку (репродукція); $\mathrm{M}_{0}, \mathrm{M}_{1}, \mathrm{M}_{2}, \mathrm{M}_{3}$ - ФПМ відповідно для оригіналу, фотоформи, друкарської форми та відбитку; $\mathrm{G}_{1}, \mathrm{G}_{2}, \mathrm{G}_{3}$ - сукупність чинників, що впливають на коливання величини ФПМ відповідно у системі «оригінал-відбиток» 
На основі регресійного аналізу експериментальних даних $[17,18]$ та програмного забезпечення Microsoft Excel 2003 було розраховано математичну модель процесу репродукування у вигляді лінійного рівняння регресії для оцінки якості процесу репродукування за показником ФПМ зображення:

$$
\begin{gathered}
y=0,821+0,030 x_{1}+0,008 x_{2}- \\
-0,01 x_{3}-0,02 x_{4}-0,008 x_{1} x_{3}+ \\
+0,008 x_{1} x_{4}-0,008 x_{3} x_{4}+ \\
+0,101 x_{1} x_{3} x_{4},
\end{gathered}
$$

де умовні позначення регресійної моделі $\mathrm{x}_{1}, \mathrm{x}_{2}, \mathrm{x}_{3}$ та $\mathrm{x}_{4}$ відповідають параметрам підсис-

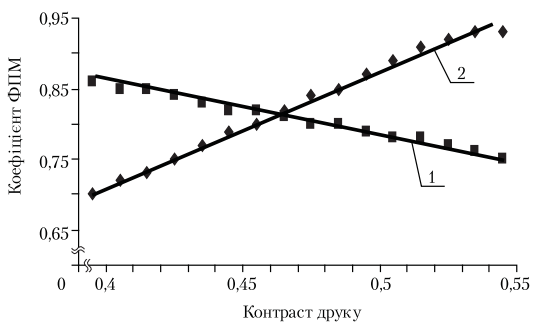

a

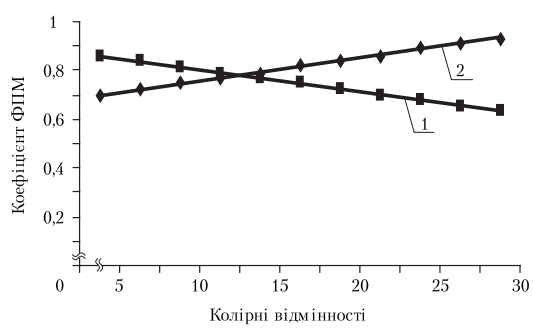

B теми «оригінал-фотоформа» відповідно контрасту зображення (K), максимальному розтискуванню растрового елементу $(\Delta \mathrm{S})$, колірним відмінностям $(\Delta \mathrm{E})$, режимам кольороподілу $\left(S_{\text {гр.к. }}\right)$.

Замінивши умовні позначення регресійної моделі $\mathrm{x}_{1}, \mathrm{x}_{2}, \mathrm{x}_{3}$ та $x_{4}$ на параметри системи «оригінал-відбиток» отримуємо:

$$
\begin{gathered}
\mathrm{M}=-1,7164+5,3483 \cdot \mathrm{K}+ \\
+0,0011 \cdot \Delta \mathrm{S}+0,1431 \cdot \Delta \mathrm{E}- \\
-0,0316 \cdot \mathrm{S}_{\text {гр.к }}-0,2992 \cdot \mathrm{K} \cdot \\
+\Delta \mathrm{E}-0,0671 \cdot \mathrm{K} \cdot \mathrm{S}_{\text {гр.K }}+ \\
+0,0041 \cdot \mathrm{K} \cdot \Delta \mathrm{E} \cdot \mathrm{S}_{\text {гр.к. }} \cdot(16)
\end{gathered}
$$

Побудоване регресійне рівняння (16) дозволяє визначити

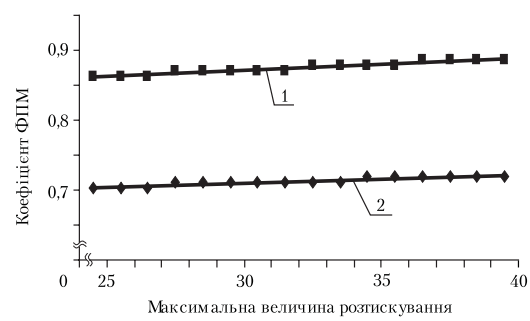

б

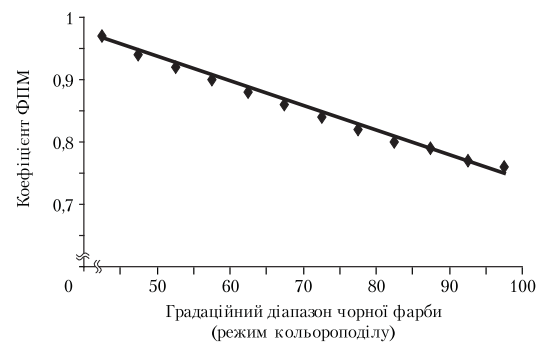

$\Gamma$

Рис. 2. Вплив параметрів процесу репродукування на коефіцієнт ФПМ зображення оригіналу: а - контраст друку (К); б - максимальна величина розтискування $(\Delta S)$; в - колірні відмінності $(\Delta \mathrm{E})$; г - режим кольороподілу $\left(\mathrm{S}_{\text {гр.к }}\right): 1-\mathrm{GCR}$ Maximum (градаційний діапазон чорного кольору $\mathrm{S}_{\text {гр.к. }}=98$ \%); $2-$ UCR (градаційний діапазон чорного кольору $S_{\text {гр.к. }}=45 \%$ ) 
характер впливу найголовніших параметрів процесу репродукування на якість відтворення нейтрально-сірих тонів у системі «оригінал-відбиток», що визначається за допомогою розрахунку коефіцієнту ФПМ репродукції (рис. 2, а-г).

Згідно рис. 2, а-в для різних режимів кольороподілу при зростанні показників колірних відмінностей та контрасту друку значення коефіцієнту ФПМ для режиму GCR Maximum буде знижуватися, а для режиму UCR, навпаки збільшуватися. Це пояснюється більшим показником градаційного діапазону чорного кольору $\left(S_{\text {гр.к. }}\right)$, наприклад, для режиму GCR Maximum, який при синтезі темних тонів нейтрально-сірого тону складається переважно із чорної фарби, що значно ускладнює можливість управління якістю репродукції в умовах зниженої стабільності процесу друкування.

Аналіз залежності величини коефіцієнта ФПМ від режиму кольороподілу (див. рис. 2, г) дозволяє констатувати, що максимальний ФПМ із наявними мінімальними впливами інших операторів забезпечується при застосуванні режиму UCR.

\section{Висновки}

1. На підставі застосування теорії множин та правил комбінаторики було розвинуто технологічні основи репродукування шляхом встановлення найбільш суттєвих параметрів, що впливають на якість відтворення інформації у системі «оригінал-відбиток»: інтервал оптичної густини $(\Delta d)$; величина спотворень відносної площі растрових елементів $(\Delta s)$; лініатура растру $\left(d_{\text {л.р. }}\right)$;

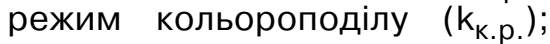
колірні відмінності $(\Delta \mathrm{E})$; баланс «по-сірому» ( $\left.\mathrm{k}_{\text {б.с. }}\right)$; роздільна здатність вивідного пристрою $\left(\mathrm{n}_{\text {р.з. }}\right)$; алгоритм растрування ( $\left.\mathrm{x}_{\text {a.p. }}\right)$.

2. На основі методики визначення ФПМ зображення розроблено модель технологічного процесу репродукування плоским офсетним друком, що дозволяє прогнозувати вплив відхилень системи «оригінал-відбиток» на стабільність відтворення оптичних властивостей тонового оригіналу.

3. Аналіз побудованої регресійної моделі процесу репродукування дозволяє констатувати, що максимальний коефіцієнт ФПМ із наявними мінімальними впливами інших операторів у процесі друку забезпечує режим кольороподілу UCR, а саме при значенні $S_{\text {гр.к. }}=0,45 \%$ коефіцієнт ФПМ складає $\mathrm{M}_{3}=0,97$.

1. Журнал KBA Process. - no. 3 (Combining hybrid inks, overprint varnishes and UV coatings in sheetfed offset). - 2006. - 64 p. 2. Стефанов С. Допечатная подготовка публикаций [Електронний ресурс] / Стефан Стефанов // Компьюарт. - 2003. - № 4. - Режим доступу до журн. : http:// compuart.ru/Article.aspx?id=8659. 3. Кувшинов М. Доказательство цвета [Електронний ресурс] / Михаил Кувшинов // Publish. - 2005. - № 6. - Peжим доступу до журн. : http://www.publish.ru/publish/2005/06/4053676. 4. Грекова Т. Скорая помощь для печатника, или измеряем цвет быстро и безошибочно / Татьяна Грекова // Publish. - 2005. - № 8. - C. 78-85. 
5. Гудилин Д. Денситометрия в офсетной печати [Електронний ресурс] / Дмитрий Гудилин // Компьюарт. - 2003. - № 1. - Режим доступу до журн. : http://compuart.ru/Article.aspx?id=8351. 6. Стефанов С. Цвет ready-made или Теория и практика цвета / С. Стефанов, В. Тихонов. - М. : РепроЦентр М, 2005. -320 с. 7. Каныгин Н. И. Цветовоспроизведение изобразительной информации репродукционными системами / Н. И. Каныгин. - М. : МГУП, 1998. - 188 с. 8. Величко О. М. Опрацювання інформаційного потоку взаємодією елементів друкарського контакту: Монографія / Олена Михайлівна Величко - К. : Видавничо-поліграфічний центр «Київський політехнік», 2005. - 264 с. 9. Дыдышко С. И. Разработка метода контроля качества печатных оттисков с использованием объемного моделирования печатных изображений: Автореферат диссертации. - М. : МГУП. 2009. - 22 с. 10. Пожарский А. О. Разработка метода оптимизации цветовых характеристик триады для цветной печати: Диссертация. - М. : МГУП. $-2007 .-240$ с. 11 . Vadim Sevryugin. Studying the influence of the recording process factors on the half-tone dots quality parameters / Vadim Sevryugin, Yuri Andreev // International Circular of Graphic Education and Research. - 2008. - No. 1. - Р. 29-34. 12. Панкин П. В. Разработка методики анализа точностных и скоростных характеристик фото- и формовыводных устройств: Автореферат диссертации. - М. : МГУП. - 2006. - 22 с. 13. Снежко Е. В. Разработка методики автоматизированной настройки устройств записи полиграфического изображения: Автореферат диссертации. - М. : МГУП. - 2006. - 19 с. 14. Штефтель 3. Г. Теорія ймовірності / 3. Г. Штефтель. - К., 1994. 15. Андреев Ю. Функция передачи модуляции для оценки полиграфических репродукционных систем / Ю. Андреев, Т. Макеева. // Полиграфия. - 2007.- № 4. - С. 30-32. 16. Зоренко Я. В. Методика регресійного аналізу для оцінки чинників управління у системі «оригінал-відбиток» / Я. В. Зоренко // Технологія і техніка друкарства. Збірник наукових праць ВПІ, НТУУ «КПІ». - 2009. - № 4(26). - С. 47-52. 17. Зоренко Я. В. Вплив технологічних параметрів репродукування на тонота кольоровідтворення / Я. В. Зоренко // Квалілогія книги: Тези доповідей. - Львів : УАД. - 2010. - С. 18-19. 18. Зоренко Я. В. Репродукційнографічні характеристики тиражних відбитків / Я. В. Зоренко, О. М. Величко // Упаковка. - № 2. - 2011. - С. 48-51.

Рецензент - В. В. Степанець, к.Т.н., доцент, НТУУ «КП|»

Надійшла до редакції 12.09.11 